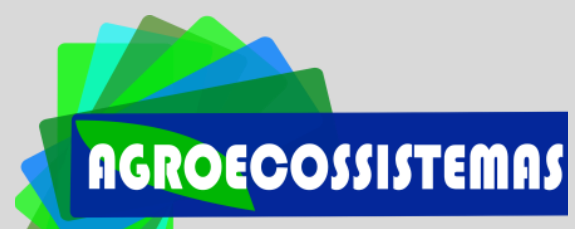

Núcleo de Meio Ambiente Universidade Federal do Pará Rua Augusto Corrêa, 01, Guamá Belém, Pará, Brasil https://periodicos.ufpa.br/index.php/agroecossistemas

Aline Dias Brito Instituto Federal do Pará - Campus Castanhal alinedbrito@outlook.com

Roberta de Fátima Rodrigues Coelho Instituto Federal do Pará - Campus Castanhal roberta.fatimacoelho@gmail.com

Louise Ferreira Rosal

Instituto Federal do Pará - Campus Castanhal louiserosal@gmail.com

\section{OS EXTRATIVISTAS DE ANDIROBA EM PROJETOS DE ASSENTAMENTOS AGROEXTRATIVISTAS (PAEX) DA VÁRZEA DE IGARAPÉ-MIRI, PARÁ, BRASIL}

RESUMO: A Carapa guianensis Aubl. (andiroba) possui grande potencial de exploração extrativista nas várzeas do município de lgarapé-Miri. Apesar da riqueza florística nesse ecossistema, poucas são as informações sobre as características da espécie e o que ela representa aos extrativistas. Esta pesquisa teve como objetivo traçar o perfil dos extrativistas que desenvolvem atividade com andiroba em Projetos de Assentamentos Agroextrativistas (PAEX) das várzeas do Município de Igarapé-Miri, PA. Como ferramenta metodológica foram aplicados questionários com 14 extrativistas que trabalham com andiroba em quatro PAEX nas ilhas Mamangal, Mutirão, Jarembú e Buçu. Utilizou-se também a metodologia snowball ou "Bola de Neve". Os resultados mostraram que a maioria dos extrativistas é de mulheres. Sobre o trabalho com a espécie, quatro são coletores, quatro são coletores e extratores e seis são extratores. A coleta de sementes é feita manualmente e acontece principalmente nos Sistemas Agroflorestais (SAFs) no o período que a Euterpe oleracea Mart (açaí) está na entre safra. A andiroba possui grande importância no contexto social, econômico e cultural dos extrativistas do PAEX de Igarapé-Miri além de renda, esta atividade tem proporcionado a conservação das andirobeiras. No entanto, é necessário sejam realizados estudos sobre a gestão dos recursos naturais na região, resguardando valores e saberes tradicionais na forma de propagação, manejo, coleta e conservação da andiroba.

PALAVRAS-CHAVE: Amazônia, Extrativismo, Produtos florestais não madeireiros.

\section{THE EXTRACTIVISTS OF ANDIROBA IN AGRO- EXTRACTIVE PROJECT (PAEX) ON FLOODPLAIN OF IGARAPÉ-MIRI, PARÁ, BRAZIL}


ABSTRACT: The Carapa guianensis Aubl. (andiroba) has great potential for extractive exploration in the floodplains of the municipality of Igarapé-Miri. Despite the floristic richness in this ecosystem, there is little information about the characteristics of the species and what it represents to extractive industries. This research had as objective to trace the profile of the extractive industries that develop activity with andiroba in Projects of agroextrativistas Settlements (PAEX) of the floodplains of the municipality of Igarapé-Miri, PA. As a methodological tool questionnaires were applied with 14 extractive industries that work with andiroba in four PAEX in Solomon Mamangal, Mutirão, Jarembú And Buçu. We also used the methodology snowball. The results showed that the majority of extractive industries is women. About the job with the species, four are collectors, four are collectors and extractors and six are extractors. The collection of seeds is done manually and happens mainly in Agroforestry Systems (SAFs) in the period that the Euterpe oleracea Mart (Açai) is in between harvest. The andiroba has great importance in social, economic, and cultural context of the extractive industries of PAEX of Igarapé-Miri besides income, this activity has provided the conservation of andirobeiras. However, it is necessary to be conducted studies on the management of natural resources in the region, protecting values and traditional knowledge in the form of propagation, management, collection and conservation of the andiroba.

KEYWORDS: Amazon, Extractivism, Non-timber forest products.

\section{PERFIL DE LOS EXTRACTIVISTAS DE ANDIROBA EN PROYECTOS DE ASENTAMIENTOS AGROEXTRACTIVISTAS (PAEX) DE LA VÁRZEA DE IGARAPÉ-MIRI, PARÁ, BRASIL}

RESUMEN: La Carapa guianensis Aubl. (Andiroba) tiene un gran potencial para la exploración extractiva en las llanuras del municipio de Igarapé-Miri. A pesar de la riqueza florística de este ecosistema, existe poca información acerca de las características de la especie y lo que representa a los extractivistas extractivas. Esta investigación tuvo como objetivo trazar el perfil de las industrias extractivas que desarrollen actividad con Agroextrativistas andiroba en proyectos de asentamientos (PAEX) de las llanuras de inundación del municipio de Igarapé-Miri, PA. Como herramienta metodológica se aplicaron cuestionarios con 14 industrias extractivas que funcionan con andiroba en cuatro en PAEX Mamangal Salomón, Mutirão, y Jarembú Buçu. También utilizamos la metodología snowball o "bola de nieve". Los resultados mostraron que la mayoría de las industrias extractivas, es el de las mujeres. Acerca del trabajo con las especies, cuatro son coleccionistas, cuatro son coleccionistas y extractores y seis son extractores. La recolección de semillas se realiza manualmente y sucede principalmente en sistemas agroforestales (SAE) en el período que el Euterpe oleracea Mart (Açai) está entre la cosecha. La andiroba tiene gran importancia en el 
contexto social, económico y cultural de las industrias extractivas de PAEX de lgarapéMiri además del ingreso, esta actividad ha facilitado la conservación de andirobeiras. Sin embargo, es necesario que se llevaron a cabo estudios sobre la gestión de los recursos naturales en la región, la protección de valores y conocimientos tradicionales en la forma de propagación, gestión, recolección y conservación de la andiroba.

PALABRAS CLAVES: Amazon, La industria extractiva, Los productos forestales no madereros.

\section{INTRODUÇÃO}

As comunidades rurais manifestam suas percepções sobre os espaços produtivos a partir de suas relações com o ambiente e com a sua cultura em que os recursos vegetais, podem ser destacados em diversas etnocategorias de uso (DAVID; PASSA, 2016).

Os ecossistemas de várzea são um dos mais ricos em produtividade biológica, biodiversidade e recursos naturais na Amazônia (SILVA; OLIVEIRA, 2016). As florestas de várzea do estuário amazônico, abrigam inúmeras espécies não madeireiras com potencial econômico, sendo capaz de promover o uso sustentável e a geração de renda para as populações amazônicas. Os Produtos Florestais não Madeireiros (PFNM) são os produtos oriundos da floresta como cascas, resinas, fibras, sementes, frutos que podem ser destinados para fins doméstico e econômicos (ELIAS; SANTOS, 2016).

Os PFNM's são vistos como alternativas ao desenvolvimento sustentável na Amazônia, pois não há a necessidade da supressão da cobertura florestal, sendo, portanto, um dos fatores que podem diminuir a taxa de desmatamento das florestas (SANTANA et al., 2016). Além disso, do ponto de vista ambiental, a coleta de PFNMs tem um menor impacto nas florestas, comparados a outras formas de usos da terra, como a extração de madeira, pecuária e outros usos da terra, os quais implicam em conversão da floresta.

As áreas de várzeas do município de Igarapé-Miri, região do Baixo Tocantins, apresentam grande 
potencial para a coleta de PFNM. O município já trabalha com a extração comercial do palmito e do fruto de Euterpe oleracea Mart. (açaí), sobressaindo-se na economia local, por ser o principal produto de autoconsumo e renda das famílias ribeirinhas. Além do açaí, esses ecossistemas possuem diversidades de espécies vegetais, de caráter medicinais, alimentícios, ornamentais, condimentares e artesanais, que podem ser usados de forma sustentável para consumo e renda pelas populações locais, principalmente durante a entre safra do açaí.

Entre as espécies vegetais, a Carapa guianensis Aubl. (andiroba) possui grande potencial de exploração extrativista não madeireira, de modo que o óleo obtido das sementes é utilizado como matéria prima, para produção de cosmético, e para fins medicinais. Brito et al. (2016) destacam que essa espécie é consagrada e apreciada pelo mercado local das várzeas de Igarapé-Miri, pela diversidade de usos e características promissoras de renda, estando associadas com outras espécies de caráter comercial, como Mauritia flexuosa L. f (buriti), Hevea brasiliensis Mart (seringueira), Astrocaryum murumuru Mart. (murumuru) e Virola surinamensis (Rol.) Warb (ucuúba/virola.)

Nas comunidades tradicionais, o óleo ou azeite de andiroba é amplamente conhecido e utilizado pela população amazônica, pelas propriedades fitoterápicas, principalmente como anti-inflamatório, contra dores de garganta, artrite e machucados; como repelente natural e como base para produtos emolientes (FERREIRA et al., 2010; ABREU et al., 2014). O óleo de andiroba possui grande potencial para promover a valorização das florestas devido sua demanda no mercado e versatilidade, tanto medicinal atribuído ao óleo, como matéria-prima na fabricação de cosméticos (SANTOS; PELLICCIOTTI, 2016).

Apesar do potencial produtivo e econômico que a andiroba nas várzeas de Igarapé-Miri, a maioria das 
pesquisas nesse município ainda estão voltados para a cultura do açaí, e poucas são as informações sobre as características da espécie, sobre os conhecimentos ecológicos, tradicionais tanto no campo da práxis, quanto no campo simbólico, nos aspectos produtivos e econômicos que ela representa aos extrativistas.

Por essa razão, é de grande importância os estudos sobre espécies com potencial de comercialização na Amazônia, para que dessa forma, possam ser gerados dados confiáveis para propor ações que visem melhores condições de manejo, e promover a valorização da floresta. Para Calle et al. (2014) o estágio do conhecimento científico é relativamente amplo no âmbito das características do extrativismo da andiroba e no seu potencial de exploração, mas, ainda tornam-se necessários estudos que estabeleçam novas abordagem sobre as perspectivas e as realidades das populações manejadoras dos recursos florestais a partir do conhecimento local.
Além disso, estudos dessa natureza, reforçam a importância sobre a produção/conservação das espécies nativas e dos estoques disponíveis e as relações entre homem e natureza. Nesse contexto, esse trabalho teve como objetivo traçar o perfil dos extrativistas que desenvolvem atividade com Carapa guianensis Aubl (andiroba) em Projetos de Assentamentos Agroextrativistas (PAEX) das várzeas do Município de Igarapé-Miri, Pará, Brasil.

\section{MATERIAL E MÉTODOS}

A pesquisa ocorreu no Município de Igarapé-Miri, localizado na região do Baixo Tocantins, entre as coordenadas $48^{\circ} 57^{\prime} 35^{\prime \prime} \mathrm{S}$ e $01^{\circ} 58^{\prime} 30^{\prime \prime} \mathrm{W}$, mesorregião do nordeste paraense, a 78 Km da capital do estado do Pará. Tem área territorial de 1.996,790 km² e índice populacional de 62.355 habitantes (IBGE, 2018).

O clima nessa região é do tipo tropical, do tipo Am de acordo com a Köppen, temperatura média anual de $27^{\circ} \mathrm{C}$, umidade relativa de $80 \%$ e precipitação pluviométrica anual acima 
de 2.000mm (ALVARES et al., 2013). A vegetação é formada de florestas secundárias com presença de cultivos agrícolas. Na área de várzea vegetação característica e de espécies hidrófilas (água) e latifoliadas (de folhas largas), intercaladas com palmeiras locais (REIS; ALMEIDA, 2012).

Os dados sobre o perfil dos extrativistas foram coletados nas ilhas Mamangal, Mutirão, Buçu e Jarimbu. Essas ilhas fazem parte de Projetos de Assentamentos Agroextrativistas (PAEX). De acordo com o relatório dos projetos de reforma agrária divulgado pelo Instituto Nacional de Colonização e Reforma Agrária (INCRA) no ano de 2017, essas ilhas foram regularizadas e destinadas à reforma agrária a partir do ano de 2005. (INCRA, 2017).

A pesquisa foi de cunho qualitativo, e para a coleta de dados, foram realizadas entrevistas com auxílio de questionários estruturados e semiestruturados, abordando os aspectos sociais, como identificação, nível educacional, idade; aspectos produtivos, como uso e acesso à terra, tipos de sistema de produção, finalidade/uso da andiroba e aspectos econômicos.

Os entrevistados foram selecionados por amostragem não probabilística, através da metodologia snowball ou "Bola de Neve" apresentada por Vinuto (2014), em que os participantes iniciais de um estudo, indicam novos participantes ao pesquisador, que por sua vez indicam novos participantes e assim sucessivamente. O uso da técnica é encerrado quando os novos entrevistados passarem a repetir informações já adquiridas em entrevistas precedentes, ou até que seja alcançado o objetivo proposto.

Este procedimento permitiu alcançar 14 extrativistas, pois são poucos que trabalham com a atividade extrativista da andiroba nas várzeas do municipio, sendo quatro no PAEX Ilha Mamangal, com um total de 606 famílias assentadas; oito do PAEX ilha Mutirão com 240 famílias assentadas; quatro no PAEX Ilha Mamangal com 606 Famílias assentadas; um no PAEX Iha Buçu com 113 famílias assentadas e 
um no PAEX Ilha Jarimbu com 910 famílias assentadas.

As entrevistas foram gravadas e para o consentimento na participação da pesquisa, foram disponibilizados aos respondentes o Termo de Consentimento Livre e Esclarecimento (TCLE), de acordo com as diretrizes estabelecidas pela Resolução $n^{\circ}$ 466/2012, com todas as informações pertinentes à pesquisa, esclarecendo que o estudo é destinado apenas para fins acadêmicos, sem qualquer relação com finalidades econômica e comercial (BRASIL, 2012).

Foram atribuídos códigos em forma de letras aos sujeitos da pesquisa para preservar a identidade dos informantes, conforme sugerido por Padilha et al. (2004), garantindo o máximo de cuidado com o anonimato dos informantes e protegendo sua identidade para que dessa forma possa-se revelar com mais propriedade os dados da pesquisa sem comprometer o entrevistado.

A pesquisa foi cadastrada na plataforma Sistema de Autorização e Informação em Biodiversidade (SISBio), que permite aos pesquisadores autorizações para atividades com finalidade científicas em unidades de conservação federais e caverna regida pela instrução Normativa nº 03 de 01 de setembro de 2014 (BRASIL, 2014). Os dados obtidos nos questionários foram tabulados em planilha no programa Excel 2010 e analisados por meio de estatística descritiva.

\section{RESULTADOS E DISCUSSÃO}

Observou-se que a maioria dos extrativistas que coletam sementes são mulheres correspondendo a 11 dos entrevistados. Os entrevistados possuem idade entre 36 e 78 anos, desses, 64\% encontra-se acima de 50 anos. Os aspectos relacionados à idade dos extrativistas, destacam que os jovens se encontram ausentes da atividade e o trabalho com sementes é preferencialmente desenvolvido por pessoas de idade mais avançada, refletindo uma geração que aprendeu com os antepassados e ainda preserva os conhecimentos adquiridos através da herança cultural. 
As transmissões de saberes e a sua

valorização contribuem para a preservação de tradições milenares (PELEGRINI; FUNARI, 2017). Para Miranda (2009) o etnoconhecimento ou conhecimentos tradicionais são produzidos por povos indígenas, afrodescendentes e comunidades locais de etnias específicas, transmitidos de geração em geração, sendo conhecimentos dinâmicos que se encontram em constante processo de adaptação e são transmitidos principalmente pela oralidade em base de valores, formas de vida e crenças mítica, desenvolvidos à margem do sistema social.

Em relação ao nível de escolaridade, observou-se que a maioria dos entrevistados possui baixa escolaridade. Entre as mulheres, nove não chegaram a concluir o ensino fundamental, uma não conclui o ensino médio e uma iniciou o ensino superior, mas não finalizou o curso em função da necessidade de trabalhar para contribuir na renda familiar. Em relação aos homens, nenhum dos entrevistados concluiu o ensino fundamental.

Resultados semelhantes foram encontrados por Monte et al. (2016) e Soares et al. (2017) ao estudarem os extrativistas do município de Uruará e Salvatera no estado do Pará. Os autores constataram que os extrativistas, na sua maioria são constituídos por pessoas com baixa escolaridade, associada a pouca oportunidade de estudo. Essa realidade sinaliza a problemática da educação no campo, e isso mostra o quanto é importante o acesso à informações e novas tecnologias, que são essenciais para o desenvolvimento do espaço rural (SOARES et al., 2017).

No que tange o trabalho com a andiroba, verificou- se que dos 14 entrevistados, quatro são coletores de sementes e fazem apenas a venda de sementes de andiroba como uma oportunidade de renda, uma vez que, não possuem conhecimento e a prática de extração de óleo. Quatro são coletores de sementes e extratores de óleo, coletam as sementes tanto para a venda, quanto para extração do óleo e 
- óleo extraído é destinado para autoconsumo e venda, desta maneira, visam o aumento da renda familiar. Seis são extratores de óleo, coletam as sementes apenas para a extração do óleo que são destinados a venda e ao uso pessoal.

A organização social de trabalho nas várzeas de Igarapé-Miri é bem diversificada, a maioria dos extrativistas são filiados à cooperativas e associações, sendo que seis fazem parte da Cooperativa Agrícola dos Empreendedores Populares de Igarapé-Miri (CAEPIM) e da Associação dos Minis e Pequenos Produtores Rurais de Igarapé-Miri (Associação Mutirão); quatro somente da CAEPIM; um da CAEPIM e do sindicato dos trabalhadores rurais; um da CAEPIM e da colônia de pescadores, um do Sindicato dos Trabalhadores e Trabalhadoras Rurais e um não participa de nenhuma organização social.

Dentre as organizações sociais, a CAEPIM realiza a comercialização das sementes oleaginosas para uma empresa multinacional desde o ano de
2008 para a produção de cosmético, e tem um papel importante para o fortalecimento da cadeia de produtos da sociobiodiversidade das várzeas do município contribuindo para economia tradicional local.

A partir disso, a atividade de coleta de sementes tornou-se promissora na região, como relatado pela extratora $\mathrm{A}$ "[...] a cooperativa mostrou a proposta e a partir disso começamos a passar as sementes para a venda, para ganhar um dinheirinho, todo dinheirinho que entra é bem-vindo". A proposta de venda de sementes estimulou o interesse dos extrativistas que não sabiam realizar a extração de óleo de andiroba, a se interessar pela coleta das sementes, proporcionando uma nova oportunidade de fonte de renda.

A organização social dos extrativistas é uma estratégia para fortalecer o trabalho coletivo e, assim, viabilizar a comercialização de produtos. Lira; Chaves (2016) destacam o poder das organizações sociais na Amazônia, a partir das suas singularidades criando coletivamente mecanismos para atender as 
necessidades básicas e a

potencialidade das populações, levando em consideração os conhecimentos tradicionais. Para Ribeiro et al. (2017), essas organizações além de favorecer o desenvolvimento local, também fortalecem as trocas de experiências e a convivência entre as pessoas.

O núcleo familiar dos extrativistas, possui em média seis pessoas por unidade de produção familiar (UPF). A dinâmica do trabalho para a manutenção das unidades produtivas é desenvolvida a partir da divisão social de trabalho de homens e mulheres.

As mulheres desempenham força de trabalho diversificada dentro do núcleo familiar extrativista, conciliando - trabalho doméstico a outras atividades dentro e fora das UPF, sendo as principais responsáveis pela coleta de sementes e extração de óleo de andiroba. Os homens são os principais responsáveis pelo extrativismo da Euterpe oleracea Mart e do manejo das UPF, desenvolvendo paralelamente atividades secundárias como produção de hortaliças e a pesca, mas participam da coleta de andiroba.

Estudos realizados por Mota et al. (2014) entre as catadoras de mangaba no estado de Sergipe e Soares et al. (2017) em Salvaterra, Ilha do Marajó (Pará), destacaram que as mulheres eram as principais responsáveis pelo extrativismo, e através da organização de trabalho, controlam os recursos da comercialização das sementes, utilizando no sustento da família, denotando o exercício de autonomia sobre essas atividades. Silva (2009) e Silva et al. (2010) destacaram que a prática de trabalho associado a andiroba realizado por mulheres, ocorre em função dos conhecimentos a cerca dessa espécie, sendo também as principais responsáveis pela transmissão de conhecimentos a geração futura.

Conforme Mota et al. (2014), em pesquisa sobre a organização do trabalho familiar no extrativismo, as organizações do trabalho familiar apontaram o desenvolvimento das atividades, em que cada função é realizada de acordo com o produto, 
suas condições de coleta e padrões culturais.

Nesse sentido, as mulheres possuem um papel significativo no extrativismo da andiroba, sendo as principais responsáveis em reproduzir os conhecimentos dos seus antepassados, contribuindo na conservação da espécie no ecossistema local, mediante aos valores socioculturais enraizados pela cultura local.

Tais circunstâncias apontam que a participação das mulheres na esfera produtiva da andiroba nas várzeas do município, reflete a importância do papel social que esta atividade representa para esse grupo social, por inverter os valores culturais, consolidando o empoderamento das mulheres em garantir recursos financeiros para o sustento familiar.

No que diz respeito ao tamanho das UPF dos entrevistados, mesmo se tratando de áreas de uso coletivo, todos afirmaram ser donos da terra em que vivem, essas áreas possuem em média oito hectares (ha) e a herança consiste em ser principal fonte de legitimação do direito ao uso da terra, citado por dez extrativista, seguidos da concessão de uso da terra citado por dois e pela posse da terra relatado por dois.

Por se tratar de PAEX, as famílias deveriam possuir o Contrato de Concessão de Uso (CCU), um documento de titulação de uso da terra fornecida pelo INCRA, órgão responsável pela emissão da titulação ou concessão de uso para extrativistas e ribeirinhas que usam a floresta para sua sobrevivência. No entanto, a maioria dos entrevistados não possui conhecimento sobre o que são os PAEX e nem o CCU da terra onde vive. Essa problemática pode estar relacionada com a dinâmica de ocupação da terra, uma vez que, os PAEX das ilhas estudadas começaram a ser implantados ano de 2005 e a maioria dos extrativistas está há mais de 40 anos residindo na localidade, e esse período pode ter sido importante para a consolidação do acesso à terra através das relações de parentesco.

Sauer e Castro (2017) destacaram que as relações com a terra, parentesco, território, ancestralidade, 
tradições e práticas culturais próprias de uma categoria social, impactam no direito de propriedade e de posse, caracterizando de um lado a diversidade cultural, a capacidade criativa e de adaptação das categorias sociais e por outro, evidencia que o direto e a terra são espaços de disputa, lutas e identidades.

Quanto aos sistemas de produção, foi verificado que em oito UPF o sistema produtivo consiste sistemas agroflorestais (SAFs) e seis em quintais agroflorestais. $\bigcirc$ manejo desses agroecossistemas em sistema de manejo florestal e adoção SAFs se deu em função do extrativismo predatório realizado ao longo de muitos anos, iniciando-se deste modo, a recuperação da vegetação natural que foi exaurida (NOGUEIRA; CONCEIÇÃO 2000; REIS 2008; MAIA et al., 2016 e SILVA et al., 2018).

Estudos realizados por Silva et al. (2018) nessa região, apontou que os principais fatores que levaram os extrativistas a adotarem meios de produção, principalmente adoção de SAFs foram a diversificação da produção (37\%), seguido por segurança alimentar da família (22\%), sombreamento do açaí (15\%), renda (12\%), adubação (6\%) e outros (7\%). Nessa perspectiva, os meios de produção sustentável vêm possibilitando a produção com a conservação dos recursos naturais, a preservação das suas identidades, buscando a valorização do seu modo de vida e suas práticas.

Com relação a origem dos indivíduos de andiroba 12 entrevistados afirmaram que as andirobeiras dos sistemas produtivos são nativas e dois relataram que possuem nativas e plantadas. As coletas das sementes de andiroba são realizadas manualmente e acontece principalmente na própria UPF, são coletadas no chão, próximo à arvore matriz, ou em pontos de acumulação deslocadas pela água, na maré baixa e os critérios adotados para a seleção das sementes são: sementes novas, sem furos ou sem broca e não germinadas

As sementes germinadas são deixadas no local para que possam se desenvolver e formar uma nova planta 
dentro das UPF. As sementes furadas e brocadas pela broca-da-andiroba (Hypsipyla grandella) só é coletada por uma extratora de óleo que aproveita esse tipo de semente para produzir o óleo que vai para olaria, o restante dos extrativistas não coletam, pois são sementes danificadas, inviabilizadas para a venda e extração de óleo para fins medicinais.

Os extrativistas também aproveitam outras áreas do entorno das suas UPF para coletar sementes de andiroba, como as UPF de seus familiares e da associação Mutirão e do rio. A coleta de sementes no rio citado por um entrevistado, é possível porque esta espécie tem dispersão hidrocórica, e por essa razão podem ser disseminadas nos cursos de água pela sua leveza, que as fazem flutuar na água com facilidade. Além disso, essas sementes podem germinar enquanto flutuam favorecendo a colonização de novas áreas, através do processo de regeneração natural, uma vez que possuem alta capacidade de germinação (PEREIRA; TONINI, 2012).
Além da coleta de sementes de andiroba, cinco entrevistados coletam outras oleaginosas, como o Astrocaryum murumuru Mart. (murumuru) citado com maior frequência entre quatro destes entrevistados, seguidos de Virola surinamensis (Rol. Ex Rottb.) Warb (ucuuba) citado por três deles e Mauritia flexuosa L. (buriti) citado por apenas um extrativista. Sacramento (2011) destacou que essas espécies são características da paisagem de várzeas e igapós do estuário amazônico, sendo um importante recurso vegetal extrativista.

Sobre a importância da andiroba para os extrativistas, onze afirmaram que essa oleaginosa representa um recurso econômico estratégico para o período que não há coleta do açaí; dois relataram que a andiroba é mais importante para fins medicinais e um entrevistado relatou que a andiroba possui a mesma importância que 0 açaí, como destacado a seguir:

"No sentido financeiro é que no inverno não tem o açaí e a gente trabalha na andiroba para se manter. Começamos a comprar quando mudamos porque no 
terreno não havia andiroba, meu marido plantou e hoje a gente tira - azeite das nossas próprias andirobeira, a gente tem em média 500 andirobeira, e nós compra também dos outros. A gente vende 0 azeite para 0 sustento quando não tem o açaí. Então a renda é a andiroba e açal" (extratora C) entrevista concedida em 27 de junho de 2017.

Esse relato mostra o potencial que essa espécie possui, principalmente para os que veem nela grande oportunidade renda. A agregação de valor citada por essa extratora, incentiva outros moradores a deixarem a andiroba se desenvolver em suas propriedades proporcionando não só a expansão do comércio das sementes e óleo, como também promoção da valorização e o uso econômico dos produtos florestais não madeireiros, como forma de garantir a propagação e preservação dessa espécie para a manutenção da diversidade da várzea

Silva et al. (2018) destacaram que as atividades extrativistas ligadas aos PFNM possibilitam geração de renda e trabalho, visto que geram pouco ou quase nenhum impacto ambiental, contribuindo para a conservação das florestas.

Dos 14 entrevistados, dez realizam a extração de óleo de andiroba, sendo que cinco realizam extração por superfície inclinada e cinco em tipiti. $O$ método de extração de óleo realizado pelos extrativistas dos PAEX de lgarapé-Miri, são oriundos dos conhecimentos tradicionais e técnicas repassados principalmente pela mãe, através da oralidade, observação e prática, representam a valorização dos traços culturais familiares.

A maior parte do óleo produzido pelos extratores de óleo das várzeas miriense é destinada ao uso pessoal e venda direta ao consumidor citado por seis extrativistas; três relataram que além de uso pessoal, doam parte do óleo para a família, vizinhos e amigos; e um relatou que faz uso pessoal, vende direto ao consumidor, atravessador e para olarias.

Além disso, a andiroba é bastante versátil no uso medicinal dos extrativistas dos PAEX de Igarapé-Miri, sendo amplamente utilizado por todos os entrevistados. Os principais 
sintomas tratados e citados com maior frequência de uso foram: machucados; inflamações, principalmente na garganta; prurido (coceiras); repelente; gripe; tosse, e azia.

Quando questionados sobre a preferência do tratamento dos sintomas apresentados com essa oleaginosa, quando comparado aos remédios farmacêuticos todos os entrevistados afirmaram preferir se tratar com óleo de andiroba por ser um recurso de fácil acesso e totalmente natural capaz de curar qualquer enfermidade. Isso pode ser observado na fala da extratora A que declarou que "usamos o óleo porque é natural", e pela extratora $E$, que afirmou "nós sempre usamos e vamos usar porque é natural, e é um dos melhores remédios que se tem, esse de farmácia, não presta". O uso de andiroba para processos inflamatórios também foi relatado por Coelho et al. (2018) e Conceição et al. (2018), ao estudarem o uso de plantas medicinais por moradores de Santarém, Pará.

Dessa maneira, pode-se perceber que o óleo de andiroba faz parte da medicina local dos extrativistas, pois as distintas formas de usos e aplicações, reforçam a sua importância no contexto social das comunidades tradicionais, fortalecendo e valorizando as crenças e os conhecimentos sobre o poder de cura do óleo. Além disso, a valorização do uso medicinal do óleo também proporciona a disseminação do comercio do óleo na região na época de entre safra do açaí, possibilitando renda e o desenvolvimento local.

\section{CONCLUSÃO}

A coleta de sementes de andiroba e extração de óleo possuem grande importância no contexto social, econômico e cultural dos extrativistas do PAEX de Igarapé-Miri, principalmente por se tratar de uma espécie bastante versátil e com potencial de geração de renda. Estas atividades têm permitido a conservação das andirobeiras nas UPF, pois é uma atividade não destrutiva, comparado a outra exploração de usos da terra.

A parceria estabelecida entre uma empresa multinacional e uma cooperativa fomentou a coleta de sementes de andiroba, principalmente 
para os ribeirinhos que não sabiam realizar a extração de óleo, passando a ter possibilidades de ganho econômico com outras culturas além do açaí, fortalecendo assim a gestão sustentável dos recursos naturais, garantindo a propagação, preservação e manutenção da diversidade da várzea.

Além dos aspectos relacionado a geração de renda da atividade extrativa do óleo de andiroba, o uso medicinal deste óleo nessa região mostrou ter grande importância sociocultural, enraizado no cotidiano dos extrativistas, sendo, portanto, um elemento chave para a conservação dos conhecimentos tradicionais dos que fazem a extração tradicional e artesanal, em um universo de crenças e valores, caracterizando a identidade cultural dos extrativistas das várzeas de Igarapé-Miri.

Apesar de toda importância sociocultural e econômica da andiroba no PAEX estudados, não foi identificada a participação dos jovens inseridos nesse contexto, e isso tornase um alerta para a preservação dos conhecimentos tradicionais e de todos os saberes que estão envolvidos no processo, que vão desde os critérios de coleta à extração de seu óleo. Nesse sentido, é de suma importância ações que visem inserir os jovens nessas atividades, com apoio de instituições e que as iniciativas tenham protagonismo da própria comunidade.

\section{AGRADECIMENTOS}

Ao Conselho Nacional de Desenvolvimento Científico e Tecnológico - CNPq, pelo apoio financeiro. Ao Núcleo de Estudos em Agroecologia - NEA, pelo suporte dado a pesquisa. Aos extrativistas dos PAEX das várzeas de Igarapé-Miri, pela generosidade e receptividade, fornecendo informações importantes para a construção deste trabalho.

\section{REFERÊNCIAS}

ABREU, J. C; GUEDES, M. C.; GUEDES, A. C. L.; MERCES BATISTA, E. Estrutura e distribuição espacial de andirobeiras (Carapa spp.) em floresta de várzea do estuário amazônico. Ciência Florestal, v. 24, n. 4, p. 1009-1019, 2014.

ALVARES, C. A.; STAPE, J. L.; SENTELHAS, P. C.; MORAES, G., 
LEONARDO, J.; SPAROVEK, G. Köppen's climate classification map for Brazil. Meteorologische Zeitschrift, v. 22, n. 6, p. 711-728, 2013.

BRASIL. Normativa $n^{\circ} 03$ de 01 de setembro de 2014. Ministério do Meio Ambiente. Regulamenta a disponibilização, o acesso e o uso de dados e informações recebidos pelo Instituto Chico Mendes de Conservação da Biodiversidade por meio do SISBio. Brasília, Diário Oficial da União, 01 de setembro de 2014. Disponível em: http://www.icmbio.gov.br/sisbio/images /stories/instrucoes_normativas/INSTRU \%C3\%87\%C3\%83O_NORMATIVA_ICMB io_N\%C2\%BA_3_DE_2014_com_retifica \%C3\%A7\%C3\%A3o_do_DOU18062015. pdf Acesso em 02 out. 2018.

BRASIL. Resolução n. 466, de 12 de dezembro de 2012. Conselho Nacional de Saúde. Aprova diretrizes e normas regulamentadoras de pesquisas envolvendo seres humanos. Brasília, Diário Oficial da União, 12 dez. 2012. Disponível em: http://bvsms.saude.gov.br/bvs/saudele gis/cns/2013/res0466_12_12_2012.html. Acesso em 02 out. 2018.

BRITO, A. D.; MENDES, F. S.; COELHO, F. R.; JORDÃO, M. Implantação de sistemas agroflorestais agroecológicos em área de produção familiar na várzea do município de Igarapé-Miri, Pará. In: congresso Brasileiro de Sistema Agroflorestais, 10., 2016, Cuiabá. Anais eletrônicos... Cuiabá: UFMT, 2016. Disponível em: http://www.tmeventos.com.br/agrof20 16/trabalhos/trab2/trabalho_1979.pdf. Acesso em 13 jan.2019.
CALLE, D. A. C.; VIEIRA, G.; NODA, H. Práticas de uso e manejo tradicional de Carapa spp. (andiroba) na Reserva Extrativista do Rio Jutaí, Amazonas, Brasil. Boletim do Museu Paraense Emílio Goeldi. Ciências Humanas, v. 9, n. 2, p. 519-540, 2014.

CARDOZO, E. G.; MUCHAVISOY, H. M.; SILVA, H. R.; ZELARAYÁN, M. L. C., LEITE, M. F. A.; ROUSSEAU, G. X.; GEHRING, C. Species richness increases income in agroforestry systems of eastern Amazonia. Agroforestry systems, v. 89, n. 5, p. 901-916, 2015.

COELHO, A. A.; GAMA, J. R. V.; DA SILVA RIBEIRO, R. B.; DE ASSIS OLIVEIRA, F. Andiroba: usos e extração do óleo em área de assentamento no oeste Paraense. Terceira Margem Amazônia, v. 3, n. 11, p. 56-51, 2018.

CONCEIÇÃO, A. K. C.; Santos, L. Á. G.; Moreira, O. J. M.; Sousa, L. M. R.; Pereira, H. J. M.; Abreu, V. H. R.; Vieira, T. A. Plantas medicinais: um saber tradicional como alternativa no processo de cura. Revista Agroecossistemas, v. 10, n. 2, p. 238254, 2018.

DAVID, M.; PASA, M. Ribeirinhos e recursos vegetais: a etnobotânica em Bonsucesso, Várzea Grande, Mato Grosso. FLOVET-Boletim do grupo de pesquisa da flora, vegetação e etnobotânica, v. 1, n. 8, 2016.

ELIAS, G. A.; SANTOS, R. Produtos florestais não madeireiros e valor potencial de exploração sustentável da Floresta Atlântica no sul de Santa Catarina. Ciência Florestal, v. 26, n. 1, p. 249-262, 2016. 
FERREIRA, M. R. A.; SANTIAGO, R. R.; SOUZA, T. P.; EGITO, E. S. T.; OLIVEIRA, E. E.; SOARES, L. A. L. Development and evaluation of emulsions from Carapa guianensis (Andiroba) oil. AAPS PharmSciTech, v. 11, n. 3, p. 1383-1390, 2010.

IBGE. Instituto Brasileiro de Geografia e Estatística. Censo do município de igarapé-mirim-PA. 2018. Disponível em:

https://cidades.ibge.gov.br/brasil/pa/i garape-miri/panorama. Acesso em: 02 de jun. de 2018.

INCRA. Incra nos Estados Informações gerais sobre os assentamentos da Reforma Agrária. $2017 . \quad$ Disponível: http://painel.incra.gov.br/sistemas/ind ex.php. Acesso em: 06 de fev. 2018.

LIRA, T. M.; CHAVES, M. P. S. R. Comunidades ribeirinhas na Amazônia: Organização sociocultural e política. Interações (Campo Grande), v. 17, n. 1, p. 66-76, 2016.

MAIA, N. J. C.; DA SILVA MATOS, C.; DOS SANTOS, R. M.; PIEDADE, S. F.; DE CARVALHO, Â. R. Especificidades do sistema de produção ribeirinho: um estudo de caso de uma unidade de produção familiar em área de várzea no município de Igarapé Miri, estado do Pará. Cadernos de Agroecologia, v. 10, n. 3, 2016.

MIRANDA, M. L. C. DE. A organização do etnoconhecimento. Revista África e Africanidades, v. 1, n. 4, 2009.

MONTE, M. S.; PARAENSE, V. C.; SANTOS, L. C. B. Análise socioeconômica das famílias agroextrativistas do projeto sementes da floresta em Uruará-PA. Revista Observatorio de la Economía Latinoamericana, v.1 n. 06, 2016. Disponível:

http://www.eumed.net/cursecon/ecola t/br/16/agroextrativistas.html. Acesso em: 06 de fev.2018.

MOTA, D. M. D.; SCHMITZ, H.; SILVA JÚNIOR, J. F. D.; RODRIGUES, R. F. D. A. O trabalho familiar extrativista sob a influência de políticas públicas. Revista de Economia e Sociologia Rural, v.52, p.189-204. 2014.

NOGUEIRA, O. L.; CONCEICAO, $\mathrm{H}$. Análise de crescimento de açaizeiros em áreas de várzea do estuário amazônico. Pesquisa agropecuária brasileira, v. 35, n. 11, p. 2167-2173, 2000.

PADILHA, M. I. C.; RAMOS, F. R. S.; BORENSTEIN, M. S.; MARTINS, C. R. A responsabilidade do pesquisador ou sobre o que dizemos acerca da ética em pesquisa. Texto \& Contexto Enfermagem, v. 14, n. 1, p. 96-105, 2004

PELEGRINI, S.; FUNARI, P. O que é patrimônio cultural imaterial. São Paulo: Brasiliense, 2017. 79 p.

PEREIRA, M. R. N.; TONINI, H. Fenologia da andiroba (Carapa guianensis, Aubl., Meliaceae) no sul do estado de Roraima. Ciência Florestal, v. 22, n. 1, p. 47-58, 2012.

REIS, A. A. Estratégias de desenvolvimento local sustentável da pequena produção familiar na várzea do município de Igarapé-Miri (PA). 
2008. 128 p. Dissertação (Mestrado em Desenvolvimento sustentável) Universidade Federal do Pará., Belém, 2008.

REIS, A. A. R.; ALMEIDA, O. T. Desenvolvimento sustentável e estratégias de uso dos recursos naturais em área de várzea no Baixo Tocantins, Amazônia. In: Desenvolvimento \& Sustentabilidade. Almeida, O.T.; Figueiredo, S. L.; TRINDADE JUNIOR, S.C.C. (Organizadores) - Belém: NAEA, 2012. p.161-176.

RIBEIRO, K. A.; MOREIRA, E. S.; RODRIGUES, A. M.; DE SOUZA, A. R. Associações e o fortalecimento da agricultura familiar: um olhar sobre brasileira, uma comunidade remanescente de quilombo. Revista Desenvolvimento Social, v. 1, n. 20, p. 121-149, 2017.

SANTANA, F. A.; NOBRE, D.N.V.; CARVALHO, J. O. P.; MATOS, J. F. R. Levantamento de mercado sobre Produtos Florestais Não-Madeireiros em. Revista EM FOCO, v. 2, n. 26, p. 6675, 2017.

SANTOS, R. S.; PELLICCIOTTI, A. S. Ocorrência de Hypsipyla ferrealis Hampson (lepidoptera: pyralidae) em andiroba no estado do acre. Ciência Florestal, v. 26, n. 3, p. 995-998, 2016.

SAUER, S.; CASTRO, L. F. P. Lutas pela terra no Brasil: sujeitos, conquistas e direitos territoriais. Revista sobre Acesso à Justiça e Direitos nas Américas, v. 1, n. 2. 2017
SILVA, A. A.; DOS SANTOS, L. E.; DA SILVA CRUZ, G.; DA SILVA RIBEIRO, R. B.; GAMA, J. R. V. Potencial de comercialização de produtos florestais não madeireiros na área de manejo da reserva extrativista Tapajós Arapiuns. Acta Tecnológica, v. 13, n. 1, p. 45-63, 2018.

SILVA, A. M. F. Saberes cotidianos e azeite de Andiroba: A presença da mulher extrativista, no contexto histórico das práticas socioculturais dos sujeitos da llha de Juba, Cametá-Pa. Belém, 2009. 370 p. Dissertação (Mestrado em História Social na Amazônia) - Universidade Federal do Pará, Belém, 2009.

SILVA, E. N.; SANTANA, A. C.; SILVA, I. M.; OLIVEIRA, C. M. Aspectos socioeconômicos da produção extrativista de óleos de andiroba e de copaíba na floresta nacional do Tapajós, Estado do Pará. Revista de Ciências Agrárias, v. 53, n.1, p. 12-23. 2010.

SILVA, R. C.; OLIVEIRA, P.C. Ecofisiologia de espécies arbóreas de interesse à piscultura em várzea Amazônica. Ambiente y Sostenibilidad, v. 6, p. 17-23, 2017.

SILVA, T. F. D. A.; BRITO, A. D.; COELHO, R. R. D. F.; SOUSA, R. D. P. Potencialidade dos produtos florestais não madeireiros na várzea miriense, estado do Pará. Cadernos de Agroecologia, v. 13, n. 1, 2018.

SOARES, I. DOS. S.; OTOBO, A. O.; RIBEIRO, C. F. A.; ESPIRITO SANTO, K. R.A. Caracterização socioeconômica e de aspectos produtivos do extrativismo 
de sementes oleaginosas amazônicas na mesorregião do Marajó-Município de Salvaterra, Pará, Brasil. Revista Observatorio de la Economía Latinoamericana, v. 2, p. 1-23, 2017.
VINUTO, J. A amostragem em bola de neve na pesquisa qualitativa: um debate em aberto. Temáticas, v.22, n. 44, p. 203-220, 2014. 